\title{
AVALIAÇÃO NACIONAL DA ALFABETIZAÇÃO (ANA): UM ESTUDO PRELIMINAR
}

\author{
Graciele Lipsuch \\ Michelle Fernandes Lima ${ }^{* 1}$
}

Esta proposta de investigação insere-se no campo das políticas nacionais (Ministério da Educação/Instituto Nacional de Estudos e Pesquisas (INEP) de avaliação da Educação Básica. Resultado de estudos realizados no curso de Pedagogia (UNICENTRO/PR), o presente trabalho está vinculado ao Grupo de Pesquisa Estado, Políticas e Gestão da Educação (UNICENTRO/IRATI/PR) ${ }^{2}$.

Segundo informações do portal do INEP (2018), com o objetivo de avaliar o sistema educacional brasileiro, foi implantado o Sistema de Avaliação da Educação Básica (SAEB), que teve sua primeira aplicação em 1990. Além da Avaliação Nacional da Educação Básica (ANEB) e da Avaliação Nacional do Rendimento Escolar (ANRESC), também conhecida como Prova Brasil) as escolas receberam mais uma forma de avaliação em nível federal: a Avaliação Nacional da Alfabetização (ANA) que, a partir de 2013, também passou a compor o Sistema de Avaliação da Educação Básica.

No entanto, mudanças no SAEB foram anunciadas em coletiva de imprensa em Brasília, pelo Ministro da Educação Rossieli Soares, no dia 28 de junho de 2018. Essas mudanças previstas para efetivação, já no ano de 2019, são consideravelmente impactantes, pois alteram a estrutura do SAEB.

\footnotetext{
${ }^{(*)}$ Graciele Lipsuch. Graduada em Pedagogia pela Universidade Estadual do Centro-Oeste (UNICENTRO) Campus de Prudentópolis, PR. E-mail: gracielelipsuch@outlook.com. URL: http://lattes.cnpq.br/4525956517957424.

Michelle F.Lima. Pós-doutora pela Universidade Estadual de Ponta Grossa (PPGE/UEPG). Docente do Curso de Pedagogia e do Programa de Pós-graduação em Educação da UNICENTRO - Irati, PR. Líder do grupo de pesquisa: Estado, Políticas e Gestão da Educação. E-mail: mfernandeslima@yahoo.com. URL: http://lattes.cnpq.br/ 3326773034222088 .

${ }^{1}$ Pós Doutora pela Universidade Estadual de Ponta Grossa (PPGE/UEPG). Docente do Curso de Pedagogia e do Programa de Pós-Graduação em Educação da Universidade Estadual do Centro Oeste/UNICENTRO - Irati, Paraná Brasil. Líder do grupo de pesquisa: Estado, Políticas e Gestão da Educação. E-mail: mfernandeslima @yahoo.com. URL: http://lattes.cnpq.br/3326773034222088.

${ }^{2}$ O Grupo de Pesquisa Estado, Políticas e Gestão da Educação foi criado em 2013 e é composto por professores do Programa de Pós-Graduação em Educação (PPGE-Unicentro), professores da Unicentro (Irati e Guarapuava), além de alunos da graduação e da pós-graduação. Tem como área de conhecimento: Educação / Políticas e Gestão Educacional. Para saber mais, acessar: 〈http://www2.unicentro.br/gepoge/>.
} 
Essas mudanças são defendidas pelo MEC e apontadas como necessárias para que o SAEB possa adequar-se à Base Nacional Comum Curricular (BNCC), que norteará os currículos escolares de todas as escolas brasileiras.

Entre as mudanças anunciadas está a inclusão da avaliação da Educação Infantil no Sistema de Avaliação da Educação Básica, por meio de questionários para professores e diretores, não necessariamente com avaliações para alunos; com esta inclusão, todas as etapas da Educação Básica serão avaliadas.

As avaliações ANA e Prova Brasil, na nomenclatura que eram apresentadas, deixarão de existir, pois, todas as avaliações da Educação Básica comporão o SAEB, o que diferenciará as avaliações será a indicação da etapa de ensino, das áreas avaliadas e dos instrumentos utilizados. Neste sentido, as avaliações do SAEB serão organizadas da seguinte forma: turmas da creche e préescola, da Educação Infantil; $2^{\circ}, 5^{\circ}$ e $9^{\circ}$ anos do Ensino Fundamental; e $3^{\circ}$ ano do Ensino Médio. As matrizes de referência das avaliações também serão adequadas conforme a orientação da BNCC.

Uma mudança importante é que o $3^{\circ}$ ano do Ensino Fundamental, até então avaliado pela ANA, deixará de ser avaliado. Isso porque, a partir de 2019, o $2^{\circ}$ ano do Ensino Fundamental terá sua avaliação, pois, conforme estabelece a BNCC, o fim do ciclo da alfabetização é no $2^{\circ}$ ano, e não mais no $3^{\circ}$.

A última mudança apontada é a que consideramos a mais relevante neste trabalho, visto que o processo de alfabetização será antecipado para o $2^{\circ}$ ano do Ensino Fundamental. Pode-se entender, portanto, que a ANA que era aplicada no $3^{\circ}$ ano, será aplicada no $2^{\circ}$, a partir de 2019.

Ao entendermos que há uma relação entre o modelo neoliberal e as políticas públicas voltadas para avaliação da Educação Básica, levantamos alguns questionamentos: Como se caracteriza a Avaliação Nacional da Alfabetização? Quais os resultados dessa avaliação nas redes municipais paranaenses de dois municípios da região sudeste do Paraná? Como as Secretarias Municipais de Educação desses municípios se organizam e orientam essa avaliação externa?

O objetivo da presente pesquisa foi investigar as políticas de avaliação em nível federal, priorizando a análise da Avaliação Nacional da Alfabetização (ANA) e buscando, assim, apontar a vinculação das políticas de avaliação em nível federal com a ideologia neoliberal, bem como levantar informações referentes às características, à aplicação, público-alvo e resultados da Avaliação Nacional da Alfabetização (ANA). 
Para responder a esta problemática, os procedimentos metodológicos da pesquisa pautaram-se no estudo de diferentes autores que discutem o tema, como Kovalchuk e Lima (2010); Menegão (2016); Oliveira (2013); Sousa (2013); Santos (2007) e outros. Também foram levantados e utilizados documentos legais do Ministério da Educação (MEC) e do Instituto Nacional de estudos e Pesquisas Educacionais Anísio Teixeira (INEP), assim como os sites oficiais do INEP.

Para complementação da pesquisa, levantamos dados no site Painel Educacional do INEP (2018), os resultados da Avaliação Nacional da Alfabetização de 2013, 2014 e 2016 em dois municípios da região sudeste do Paraná. Com o propósito de verificar aspectos relacionados à ANA e ao processo de alfabetização nestas redes municipais de ensino, enviamos questionários para as Secretarias de Educação dos municípios pesquisados.

O presente artigo está estruturado em dois momentos: primeiramente, discute a relação do Estado neoliberal com as avaliações externas, apresentando, também, a contextualização do Sistema de Avaliação da Educação Básica (SAEB), dando ênfase à Avaliação Nacional da Alfabetização. No segundo momento, complementamos a pesquisa por meio dos resultados observados nas redes municipais de ensino.

\section{CONSIDERAÇÕES SOBRE AS POLÍTICAS DE AVALIAÇÃO EM LARGA ESCALA}

As políticas educacionais estão inseridas em um contexto histórico, econômico e social que, consequentemente, as influenciam. Para Oliveira (2013, p. 237) “a educação é, pois, uma prática social ampla e inerente ao processo de constituição da vida social, alterando-se no tempo e no espaço em razão das transformações sociais". Nesta perspectiva, é preciso entender o contexto em que estão inseridas as políticas educacionais, em especial as avaliativas, uma vez que elas são incentivadas e implantadas sobre influências tanto internas como, também, externas, a exemplo dos organismos internacionais.

Pensando na sociedade atual, Mascaro (2013) expõe sobre o sistema capitalista e suas implicações na sociedade; segundo o autor, a organização política do Estado atual é uma manifestação moderna, capitalista. O capitalismo, portanto, difere-se de outros modos de produção anteriores por separar o domínio econômico e o político.

Mascaro (2013) afirma, ainda, que o Estado surge e se relaciona com a dinâmica entre capital e trabalho. Assim, o Estado é necessário para a reprodução desta dinâmica e das relações sociais, tendo em vista que não se apresenta como um poder neutro. Isto porque, ao mesmo tempo em que atribui garantias jurídicas e políticas aos sujeitos, contraditoriamente mantém a lógica do 
valor, garantindo a reprodução mercantil de produção capitalista, que está associada à exploração social e do trabalho.

Kovalchuk e Lima (2010) destacam que, principalmente a partir do governo de Fernando Henrique Cardoso (1995-2002), ocorreu a instauração da ideologia neoliberal no Brasil. Esta gestão caracterizou-se "[...] pela privatização do público, pela descentralização do ensino, e práticas de controle [...]" (KOVALCHUK e LIMA, 2010, p. 03). Segundo as autoras, desde então, as políticas educacionais vêm sendo influenciadas por princípios neoliberais, priorizando atender demandas do mercado geradas pelo capitalismo.

Como expõe Maué (2013, p. 287), “a globalização econômica deixa cada vez mais evidente a vinculação que é feita entre a educação e o mercado". À escola é atribuído o papel de formar pessoas para atuar no mundo globalizado; neste sentido, a Educação contribui para a reprodução do ser social.

Considerando os argumentos apresentados, podemos afirmar que a Educação, no sistema capitalista fundado na ideologia neoliberal, assume como principal finalidade a preparação dos indivíduos para o mercado de trabalho. Mas, como podemos entender a relação do sistema capitalista e a ideologia neoliberal com as avaliações em larga escala?

No Brasil, segundo Oliveira (2013), as políticas e reformas educacionais de ajuste, implementadas principalmente a partir da década de 1990 no governo de FHC (1995-2002), visavam a modernizar o Brasil e, consequentemente, promover sua inserção na globalização econômica. Neste sentido, foram valorizadas a elevação do tempo de escolarização, enfatizando o Ensino Fundamental, também, “[...] novas formas de regulação dos sistemas de ensino e das escolas, visando maior concorrência, eficiência e produtividade" (OLIVEIRA, 2013, p. 242).

É neste contexto que o Estado assume um papel de avaliador e controlador, pois, ao investir em programas voltados à melhoria da Educação, necessita de bons dados quantitativos para comprovar seu investimento na área educacional. Como afirma Sousa (2013), o ensino básico brasileiro, atualmente, é questão de unanimidade nacional, pois é um fator social essencial para elevar o desenvolvimento econômico do país.

O Estado brasileiro, a partir da década de 1980 e sob os princípios da ideologia neoliberal, passou a avaliar os sistemas de ensino brasileiros, principalmente no que se refere à Educação Básica, por meio de avaliações em larga escala aplicadas em território nacional. 
Conforme informações do portal do INEP (2018), com o objetivo de avaliar o sistema educacional brasileiro, o Sistema de Avaliação da Educação Básica (SAEB) foi criado e teve sua primeira aplicação em 1990, configurando-se como a primeira iniciativa de conhecer o sistema educacional. A partir de 1995, o SAEB possibilitou a comparação dos desempenhos ao longo dos anos.

O SAEB foi reestruturado pela Portaria Ministerial $n^{\circ} 931$ de 21 de março de 2005 (BRASIL, 2005), e passou a ser composto por duas avaliações: a Avaliação Nacional da Educação Básica (ANEB) e a Avaliação Nacional do Rendimento Escolar (ANRESC), esta última também conhecida como Prova Brasil.

A partir da Portaria 482, de 07 de junho de 2013 (BRASIL, 2013b), a Avaliação Nacional da Alfabetização (ANA) também passou a compor o SAEB, prevista no Pacto Nacional pela Alfabetização na Idade Certa (PNAIC):

[...] a ANA traz um elemento novo que a distingue das demais modalidades de avaliação integradas ao SAEB e corrobora o caráter indutor de currículo assumido nesse cenário: ela vem acompanhada de um projeto de formação de professores e, portanto, de um projeto curricular explícito (DICKEL, 2016, p. 198).

As avaliações nacionais são desenvolvidas e aplicadas pelo INEP são as responsáveis pelos dados educacionais quantitativos, e tornaram-se um dos pontos de partida de direcionamento das políticas educacionais no Brasil.

Durante o processo de alfabetização, uma parte significativa dos alunos chega ao $3^{\circ}$ ano sem saber ler, escrever e contar. Diante desta situação, o governo criou mecanismos, como as avaliações em larga escala para o Ensino Fundamental - anos iniciais (Provinha Brasil, Avaliação Nacional da Alfabetização) e o Programa Federal Pacto Nacional pela Alfabetização na Idade Certa. Tudo isto com o objetivo de alavancar a qualidade do Ensino Fundamental - anos iniciais, momento em que acontece o processo de alfabetização.

Uma das políticas educacionais desenvolvidas foi a implantação do PNAIC, que se constitui no compromisso assumido entre os entes federados, e que tem como meta a alfabetização das crianças até os 08 anos de idade, ao final do $3^{\circ}$ ano do Ensino Fundamental, no final do Ciclo de Alfabetização. Vale destacar que a alfabetização das crianças até os 08 anos de idade está prevista no Plano Nacional de Educação (PNE 2014- 2024), na meta $05^{3}$.

\footnotetext{
3 "Meta 5: alfabetizar todas as crianças, no máximo, até o final do $3^{\circ}$ (terceiro) ano do ensino fundamental" (BRASIL, 2014, p.10).
} 
O PNAIC foi instituído pela Portaria n ${ }^{\circ} 867$ de 04 de julho de 2012 (BRASIL, 2012), e surgiu da necessidade de melhorar a qualidade do ensino durante a alfabetização. "Este Pacto é constituído por um conjunto integrado de ações, materiais e referências curriculares e pedagógicas disponibilizados pelo MEC, tendo como eixo principal a formação continuada de professores alfabetizadores" (BRASIL, 2015b, p.10). Neste sentido, Dickel (2016) afirma que o PNAIC surge no contexto de emergência, da ineficácia escolar, ao que se refere às habilidades básicas em leitura, escrita e matemática de crianças e jovens.

Assim como o PNAIC, a Avaliação Nacional da Alfabetização foi uma proposta política, que visava à melhoria dos dados quantitativos no ciclo de alfabetização brasileira. Com as mudanças no SAEB, anunciadas para o ano de 2019, a ANA deixará de existir. No entanto, certamente outras políticas educacionais voltadas para alfabetização serão implantadas, visto que o processo de alfabetização terá como ponto de referência o $2^{\circ}$ ano do Ensino Fundamental.

A Avaliação Nacional da Alfabetização tinha, como público-alvo, “[...] os estudantes matriculados na última etapa do ciclo de alfabetização, isto é, no $3^{\circ}$ ano do ensino fundamental, de turmas regulares de escolas públicas urbanas e rurais com, no mínimo, 10 estudantes matriculados" (BRASIL, 2015a, p. 21). Após sua implantação, a ANA foi aplicada em 2013, 2014 e 2016; a edição de 2015 foi cancelada. Em 2018, devido às mudanças anunciadas no SAEB, a ANA não será mais aplicada.

No Documento Básico da ANA (BRASIL, 2013a, p. 07) divulgado pelo MEC, são apresentados os principais objetivos da Avaliação Nacional da Alfabetização, que são:

i) avaliar o nível de alfabetização dos educandos no $3^{\circ}$ ano do ensino fundamental. ii) produzir indicadores sobre as condições de oferta de ensino.

iii) concorrer para a melhoria da qualidade do ensino e redução das desigualdades, em consonância com as metas e políticas estabelecidas pelas diretrizes da educação nacional.

Além de aferir os níveis de alfabetização e letramento em Língua Portuguesa e alfabetização em Matemática, a ANA buscava analisar, também, as condições de oferta de ensino. Neste sentido, eram aplicados questionários aos professores e gestores das escolas, cujo foco era gerar informações referentes às "[...] condições de infraestrutura, formação de professores, gestão da unidade escolar, organização do trabalho pedagógico, entre outras" (BRASIL, 2013a, p. 08).

Segundo Santos (2007), a qualidade na Educação considerada nas avaliações externas é a que, predominantemente, prepara os alunos para atender aos interesses do capital. Além disto, pensando no contexto da ANA, concordamos com a perspectiva de Dickel (2016, p.195): 
“defender-se-á a tese segundo a qual a ANA, como integrante do SAEB e como ação disponibilizada ao professor alfabetizador, produz efeitos sobre o controle do trabalho pedagógico e reforça a responsabilização da escola e do professor [...]”. Portanto, a ANA mostra-se mais um instrumento de controle, e apesar de não ser mais aplicada a partir de 2019, acredita-se que a avaliação do SAEB prevista para ser aplicada no $2^{\circ}$ ano seguirá os mesmos rumos da ANA. Além disso, tornara-se um instrumento muito maior de pressão docente, visto que o final do ciclo de alfabetização será antecipado, demandando maior desempenho dos professores alfabetizadores para, consequentemente, ter melhores resultados.

Menegão (2016) discute os impactos das avaliações em larga escala nos currículos escolares e afirma que tanto o currículo quanto a avaliação educacional devem ser compreendidos como resultantes de aspectos sociais, culturais, econômicos e também políticos. Isto porque a elaboração de um currículo não é arbitrária, pois ele será definido a partir da valorização de interesses ideológicos. Neste sentido, "ousamos afirmar que favorecer a totalidade da população escolar com educação de qualidade social não tem sido o escopo das políticas curriculares e, quiçá, de avaliação" (MENEGÃO, 2016, p. 643). Segundo a autora, no caso brasileiro, historicamente, o currículo foi pensado, em grande parte, a partir dos interesses ideológicos da classe dominante.

Este item apresentou algumas considerações e reflexões referentes às políticas avaliativas assumidas diante dos princípios neoliberais, no contexto da sociedade capitalista globalizada, assim como apresentou informações referentes ao SAEB e à ANA. O próximo item busca apresentar o levantamento dos resultados quantitativos da ANA, assim como as informações sobre esta avaliação nos dois municípios paranaenses pesquisados.

\section{AVALIAÇÃO NACIONAL DA ALFABETIZAÇÃO (ANA) EM DOIS MUNICÍPIOS DO ESTADO DO PARANÁ}

Visando à complementação da pesquisa, foram levantados os resultados da Avaliação Nacional da Alfabetização nas edições 2013, 2014 e 2016, por meio dos documentos legais que dispõem sobre a ANA, assim como dos sites oficiais. Neste sentido, serão apresentados brevemente os resultados da ANA nas redes municipais de educação que estudadas.

A ANA mostrou-se uma avaliação que buscava, também, diagnosticar outros aspectos ligados à alfabetização. No entanto, entendemos que não basta apenas identificar as condições de oferta de ensino, no caso da ANA, da alfabetização: é preciso usar os resultados e buscar interferir na realidade escolar, a fim de promover uma real qualidade de ensino. 
Segundo Sousa (2013), a escola é tomada como um microssistema educacional responsável pelo sucesso escolar. Sob esta perspectiva, o governo aplica provas de rendimento aos alunos com o objetivo de medir a produtividade de cada escola:

este encaminhamento, ao tempo em que se revela estimulador da competição entre escolas, responsabiliza-as, individualmente, pela qualidade de ensino e re-situando o compromisso do poder público com seus deveres, é expressão no campo educacional da defesa do Estado mínimo, em nome da busca de maior eficiência e produtividade (SOUSA, 2013, p. 265).

Assim, mostram-se os princípios neoliberais como orientadores na Educação. Kovalchuk e Lima (2010) afirmam que o papel que o Estado brasileiro assumiu diante da globalização, da ideologia neoliberal e da pressão dos organismos internacionais, foi de um estado avaliador e regulador que, para alcançar seus objetivos, implantou medidas e projetos para superar os números negativos da Educação. A partir deste contexto, surgiu a necessidade de avaliar quantitativamente os resultados desses projetos: é nesse momento que surgem as avaliações nacionais em larga escala. Nesta perspectiva, entendemos que as avaliações nacionais são uma ferramenta de controle, inclusive a ANA, pois o Estado, ao assumir princípios neoliberais, afasta-se das questões sociais, mas, ao mesmo tempo, intensifica instrumentos de controle e regulação, como se a implantação de testes fosse a única solução para resolver a questão da qualidade educacional brasileira.

A ANA era composta por testes de desempenho e questionários contextuais. Os testes de desempenho da ANA buscavam aferir os níveis de alfabetização e letramento em Língua Portuguesa e a alfabetização em Matemática. Os testes eram compostos por 20 itens objetivos de Matemática; em Língua Portuguesa também eram 20 itens, sendo 17 deles de múltipla escolha e 03 itens de produção escrita.

Os testes mediam o desempenho dos estudantes nos níveis de proficiência, que eram progressivos e cumulativos; ou seja, estavam organizados da menor para a maior proficiência. As escalas de Língua Portuguesa (leitura) e Matemática eram compostas por quatro níveis. A escala de proficiência em Língua Portuguesa (escrita) teve alteração da edição de 2013 para a edição de 2014, com a adesão de mais um nível de proficiência, passando a ser composta por cinco níveis; da edição de 2013 para 2014, houve alteração na composição das escalas de proficiências.

Menegão (2016, p. 648) pontua que “[...] a ênfase dada pela avaliação em larga escala, aos aspectos cognitivos de Língua Portuguesa e Matemática, tem induzido ao estreitamento curricular, especialmente porque promove situações em que ensinar e aprender para o teste seja a razão principal do fazer docente". A Avaliação Nacional da Alfabetização valorizava e cobrava as 
disciplinas de Língua Portuguesa e Matemática. Cabe questionar, então: as outras disciplinas não têm importância? Tomando os argumentos apresentados por Menegão (2016), entendemos que a avaliação em larga escala reduz-se ao básico. "Compreendemos, por básico, o mínimo, mas, no cenário dos testes, o básico está sendo entendido como máximo. Assistimos, desse modo, à implementação de um currículo pautado no básico" (MENEGÃO, 2016, p. 652, grifos do autor).

Apontamos os resultados da Avaliação Nacional da Alfabetização nas duas redes municipais pesquisadas, considerando os níveis de proficiência em Língua Portuguesa (leitura e escrita) e Matemática (Quadro 1 e 2). A escala de proficiência de escrita teve alteração da edição de 2013 para a de 2014; neste sentido, apenas os dados mais recentes foram utilizados.

\section{QUADRO 1. Distribuição percentual dos estudantes por nível de proficiência em leitura e matemática nas edições 2013, 2014 e 2016; e escrita nas edições de 2014 e 2016 da ANA, no Município 1}

\begin{tabular}{|c|c|c|c|c|c|c|c|c|}
\hline & \multicolumn{2}{|l|}{ Escrita } & \multicolumn{3}{|l|}{ Leitura } & \multicolumn{3}{|c|}{ Matemática } \\
\hline Níveis & 2014 & 2016 & 2013 & 2014 & 2016 & 2013 & 2014 & 2016 \\
\hline 1 & $1,80 \%$ & $2,53 \%$ & $4,41 \%$ & $6,77 \%$ & $6,40 \%$ & $5,63 \%$ & $7,29 \%$ & $4,48 \%$ \\
\hline 2 & $3,13 \%$ & $8,70 \%$ & $37,91 \%$ & $32,80 \%$ & $32,96 \%$ & $34,02 \%$ & $28,92 \%$ & $31,96 \%$ \\
\hline 3 & $1,57 \%$ & $0,56 \%$ & $46,24 \%$ & $44,45 \%$ & $45,70 \%$ & $23,35 \%$ & $22,81 \%$ & $27,18 \%$ \\
\hline 4 & $59,44 \%$ & $66,36 \%$ & $11,44 \%$ & $15,98 \%$ & $14,94 \%$ & $37,01 \%$ & $40,98 \%$ & $36,38 \%$ \\
\hline 5 & $34,06 \%$ & $21,85 \%$ & & & & & & \\
\hline
\end{tabular}

Fonte: Dados organizados pelas autoras a partir do site Painel Educacional (2018).

QUADRO 2. Distribuição percentual dos estudantes por nível de proficiência em leitura e matemática nas
edições 2013, 2014 e 2016; e escrita nas edições de 2014 e 2016 da ANA, no Município 2

\begin{tabular}{|c|c|c|c|c|c|c|c|c|}
\hline \multirow[b]{2}{*}{ Níveis } & \multicolumn{2}{|l|}{ Escrita } & \multicolumn{3}{|l|}{ Leitura } & \multicolumn{3}{|c|}{ Matemática } \\
\hline & 2014 & & 2013 & 014 & 16 & 2013 & 2014 & \\
\hline & $0,56 \%$ & $1,80 \%$ & $7,36 \%$ & $6,00 \%$ & $6,98 \%$ & $7,46 \%$ & $5,61 \%$ & $6,23 \%$ \\
\hline & $3,19 \%$ & $7,40 \%$ & $52,38 \%$ & $40,23 \%$ & $39,40 \%$ & $40,34 \%$ & $41,08 \%$ & $38,43 \%$ \\
\hline & $1,30 \%$ & $0,24 \%$ & $33,67 \%$ & $44,58 \%$ & $37,65 \%$ & $24,04 \%$ & $26,58 \%$ & $22,93 \%$ \\
\hline & $81,76 \%$ & $80,96 \%$ & $6,59 \%$ & $9,19 \%$ & $15,97 \%$ & $28,17 \%$ & $26,73 \%$ & $32,41 \%$ \\
\hline & $13,19 \%$ & $9,59 \%$ & & & & & & \\
\hline
\end{tabular}

Fonte: Dados organizados pelas autoras a partir do site Painel Educacional (2018).

Observamos, a partir dos quadros 1 e 2, que o município 1 obteve bom desempenho em Matemática nas três edições, concentrando o maior percentual de alunos no maior nível da escala. No município 2, a maioria dos estudantes está concentrada no nível 4 de Escrita, mostrando bom desempenho. Observamos, ainda, uma melhora progressiva nos níveis de leitura durante as edições. 
No entanto, a maior concentração de alunos no nível 2 de matemática é alta; em outras palavras, não obtiveram bom desempenho em matemática.

As tabelas buscam apresentar os resultados da ANA nos municípios, pois se entende que os números precisam ser considerados. No entanto, somente os números não conseguem traduzir a complexidade do sistema educacional.

Na perspectiva de Santos (2007), entendemos que o processo avaliativo que resulta na publicação de rankings de escolas, redes de ensino e entes federativos, amplamente divulgados pela mídia, contribui para práticas classificatória e excludentes, que evidenciam ideias meritocráticas que acabam, muitas vezes, vangloriando instituições, redes e regiões em detrimento de outras. Estas últimas, ao invés de receberem maior apoio pedagógico e financeiro por meio de políticas específicas, acabam sendo marginalizadas. Isto reafirma ainda mais a desigualdade social e educacional.

Além dos resultados da ANA, buscamos verificar os aspectos relacionados ao processo de alfabetização nas redes municipais de ensino, tendo em vista que é um dos objetivos desta pesquisa. Neste sentido, foi enviado um questionário semiestruturado para as Secretarias Municipais de Educação desses municípios, contendo oito questões relacionadas à formação continuada dos professores alfabetizadores, ao uso dos resultados da ANA, e outros aspectos ligados à política de avaliação e alfabetização, enfatizando aspectos relacionados à já mencionada ANA. Visando a manter o anonimato das instituições, utilizou-se a nomenclatura SME A (Secretaria Municipal de Educação A) e SME B (Secretaria Municipal de Educação B) para apresentação dos dados.

Uma das questões levantadas foi a realização do Pacto Nacional da Alfabetização na Idade Certa nos anos 2013, 2014, 2015 e 2016 no município. Ambas as Secretarias de Educação responderam que os professores alfabetizadores participaram do programa. Além do Pacto, buscamos verificar a existência de cursos específicos desenvolvidos pela SME para a formação continuada dos professores alfabetizadores que atuam no ciclo básico da alfabetização. A SME A respondeu que: "Além do PACTO, a SME oferece outros cursos que complementam a formação dos professores, alguns ministrados pela equipe pedagógica da própria secretaria, outros por editoras de livros didáticos e pedagógicos e ainda a parceria com programas e projetos”.

A SME B também afirmou que desenvolveu o Pacto nos anos mencionados, e que ele teve grande receptividade por parte dos professores. Em relação à formação continuada dos professores, a SME B afirmou que ela é oferecida por uma editora de livros. 
Apesar de afirmar que há cursos para os professores, as SME não deixam claro se esses cursos são apenas para os professores alfabetizadores. Ao serem indagadas se há algum projeto voltado para a melhoria da alfabetização no município, observamos o enfoque que a SME A faz com as parcerias com programas e projetos. Além disto, pontua que "a equipe pedagógica da SME realiza visitas nas escolas de orientação e acompanhamento pedagógico a professores e alunos; desenvolve projetos de leitura e escrita; reforço escolar e parcerias com outros programas [...]" (SME A). A SME B também menciona o reforço escolar como estratégia de melhoria da alfabetização no município:

A Secretaria de Educação entrega no início do ano o calendário de reunião mensal com gestores e coordenadores onde são discutidos os problemas pedagógicos vivenciados na rotina escolar. Como projeto que vise à melhoria da alfabetização as escolas possuem o reforço escolar (SME B).

Considerando a influência do PNAIC e da ANA na orientação política educacional do município, se ocorreu melhora na alfabetização, ambas as Secretarias de Educação responderam que sim. Dando ênfase ao PNAIC, a SME B justifica:

[...] através desse programa percebe-se a evolução dos educadores; os professores que participaram trabalharam de uma maneira diferenciada, embora alguns já apresentassem essa melhora. Em 2016 houve grande desinteresse em participarem do programa devido à falta de informação e demora para início das atividades, percebendo-se aí professores desestimulados (SME B).

A SME A afirma que tanto a ANA quanto o PNAIC influenciam na melhoria da educação do município, “[...] pois possibilitam a qualificação docente, que auxilia os alunos no processo de alfabetização e na qualidade da educação" (SME A).

Com as mudanças no SAEB previstas para 2019, o que observamos é uma descontinuidade de algumas políticas educacionais. No caso da ANA, implantada em 2013, é uma política relativamente recente que deixará de existir.

Tendo em vista as respostas das Secretarias Municipais de Educação, pontuamos as considerações de Dickel (2016, p. 204):

se consideradas as condições em que a ANA se constitui integrante do SAEB, observa-se que ela não se instaura como uma modalidade de avaliação de responsabilização forte. Mas, ao projetar seu foco para as aprendizagens das crianças, secundarizando ou omitindo informações necessárias à composição de um quadro mais complexo acerca de como ocorre o processo de alfabetização inicial, ela se eleva 
como estratégia de responsabilização dos professores pelos resultados do trabalho escolar.

Apesar de o PNAIC ter se mostrado um programa que possibilita a formação continuada dos professores e a valorização da aprendizagem lúdica por meio de materiais didáticos, tem se tornado uma ferramenta de controle e responsabilização, ao intensificar a pressão sobre professores alfabetizadores, principalmente no que se refere aos resultados da qualidade do ensino avaliados em provas de larga escala, como a ANA e Provinha Brasil.

Ao realizarem pesquisa sobre o PNAIC, Pires e Schneckenberg (2015, p. 121) concluíram, em uma de suas análises que, sobre o PNAIC, “[...] pode-se afirmar que esta é uma ação do Governo Federal que busca, num programa de formação continuada de docentes, a melhoria dos resultados educacionais nas avaliações nacionais". Observamos que as avaliações nacionais valorizam os resultados em detrimento do processo.

Sousa (2013) afirma que o sistema de avaliação estabelece mecanismos que estimulam a competição entre escolas, a exemplo do IDEB (Índice de Desenvolvimento da Educação Básica) e dos rankings nacionais, que acabam responsabilizando as escolas pelo seu sucesso ou seu fracasso nos resultados educacionais. Nesta perspectiva, intensifica-se a seletividade social na escola, premiando instituições com bons resultados e, se não punindo, promovendo ações específicas nas escolas com baixo rendimento. Além disto, há uma preparação para as avaliações, com a intensificação de treinamento para as avaliações em larga escala e a expulsão de alunos que tem pouca chance de ir bem nas avaliações: isso para não comprometer o desempenho da escola.

Considerando as respostas das SME, identificamos a orientação para a preparação para as avaliações, em especial para a ANA:

Orienta-se que os professores trabalhem em sala de aula de acordo com o que é repassado nas formações do PNAIC e também com o conteúdo proposto no planejamento curricular, que são retomados próximo a data da realização da avaliação (SME A, grifos nossos).

A SME B pontua que, "em relação a ANA a SMEC orienta os professores a trabalharem de acordo com os indicativos que serão cobrados na avaliação. Percebe-se aí nitidamente através dos resultados as escolas que executam esse trabalho antes da aplicação propriamente dita" (SME B, grifos nossos). 
Refletindo as respostas das SME, podemos afirmar, na visão de Menegão (2016), que as avaliações em larga escala também influenciam a definição do currículo, uma vez que ele deve ser pensado a fim de atender as finalidades cobradas nas avaliações em larga escala.

Considerando a utilização dos resultados da ANA, a SME A pontuou que "os resultados da ANA são utilizados [para] reflexão e análise das condições de escolaridade, do desempenho dos alunos, bem como estabelecer estratégias de melhorias na educação". Em relação a essa questão, a SME B afirmou: "os resultados da ANA foram utilizados para estabelecer critérios de avaliação docente e definir estratégias voltadas à formação continuada dos docentes” (SME B, grifos nossos).

Como expõem Schneider e Rostirola (2015, p. 500),

a implantação do Sistema de Avaliação da Educação Básica (Saeb), no ano de 1990, a partir de uma demanda do Banco Mundial, é exemplo cabal da entrada do Brasil nos preceitos do Estado-avaliador e das injunções de organizações internacionais sobre as políticas nacionais.

A ANA foi mais um instrumento de controle do SAEB, voltado para a alfabetização, uma vez que um dos motivos de sua implantação ocorreu pelos baixos índices de alfabetização do Ensino Fundamental - anos iniciais. Portanto, as avaliações nacionais tornaram-se um dos principais pontos de partida de direcionamento da política educacional, tanto em âmbito federal como municipal, no caso da ANA, como podemos observar nas respostas das SME. Além disto verificamos, nas respostas das Secretarias de Educação, o enfoque que é dado ao PNAIC e a responsabilização dos professores pelos resultados da ANA.

A SME A afirmou claramente que a ANA tem contribuído para a melhoria da alfabetização no município, “[...] pois possibilita reflexão da prática pedagógica e das metodologias utilizadas para o processo de ensino aprendizagem [...]" (SME A). Apesar de não deixar evidente a resposta da questão em relação à contribuição da ANA para a melhoria na alfabetização, a SME B, em um momento do questionário, pontuou: "Em relação à ANA, a primeira avaliação do município foi alarmante, mas depois houve uma melhora significativa” (SME B).

No que concerne à discussão e desenvolvimento de ações coletivas com professores e gestores a partir dos resultados da ANA em 2013 e 2014, visando à melhoria da alfabetização no município, a SME A afirmou que os resultados são analisados e discutidos no PNAIC. A SME B pontuou que "houve essa preocupação em trabalhar em cima dos resultados obtidos. Através de reuniões com equipe diretiva, gestores e professores" (SME B). 
Cabe refletir se realmente a ANA foi tema de reflexão e análise nas escolas e entre professores e gestores, e não apenas no PNAIC. Neste sentido, sobre as avaliações nacionais, concordamos com Menegão (2016, p. 653), que afirma:

se tomarmos por referência a trajetória que a avaliação percorre, considerando as finalidades a que se propõem e os impactos que vem acarretando nos espaços escolares, especialmente para os professores, constatamos que são tomadas certas decisões, e assumidas determinadas prioridades, que produzem efeitos bem diferentes daqueles que são anunciados pela política de avaliação.

Se realmente estamos preocupados com a qualidade educacional e não apenas com a mera reprodução de ideais capitalistas voltados para formação de trabalhadores, é preciso ir além dos testes nacionais, investigar a realidade, o contexto educacional; é preciso usar os resultados a fim de intervir nessa realidade escolar, seja por meio da formação continuada dos professores, investimentos em materiais pedagógicos, melhoria de infraestrutura escolar, valorização docente; todos esses aspectos e outros que influenciam na aprendizagem do aluno, e se não forem considerados, de nada adianta promover avaliações nacionais.

\section{CONSIDERAÇÕES FINAIS}

O objetivo desta pesquisa não foi avaliar a política de avaliação da ANA, mas caracterizar as políticas avaliativas, em especial a ANA, na visão de autores que tratam desta questão; também buscou dar a conhecer esta avaliação.

Considerando os objetivos desta pesquisa, verificamos que as políticas avaliativas implantadas a partir da década de 1990, no Brasil, passaram a fazer parte do cenário educacional fortemente influenciado por princípios neoliberais, propagados pelos organismos internacionais, principalmente pelo Banco Mundial, que orientam o Estado a assumir princípios mínimos voltados aos setores sociais, como a Educação, ao mesmo tempo em que o Estado assume a postura de avaliador, que regula e controla os resultados a fim de promover a eficiência e eficácia do setor educacional ao máximo.

Evidencia-se que as avaliações em larga escala tornaram-se pontos de partida de direcionamento da política educacional, uma vez que são aplicadas com o objetivo de avaliar quantitativamente a qualidade educacional. No entanto, é preciso questionar a que tipo de qualidade está se referindo. 
Concluímos, ainda, que a intensificação das avaliações externas tem refletido na organização escolar, seja em relação à orientação curricular, pressão docente, práticas de treinamento, seletividade e responsabilização, assim como a competitividade entre escolas, redes de ensino e até mesmo entre países, por meio de testes internacionais.

A ANA, sendo uma avaliação voltada ao processo de alfabetização aplicada no $3^{\circ}$ ano do Ensino Fundamental - anos iniciais, juntamente com o PNAIC, fez parte de um conjunto de ações propostas para a alfabetização das crianças até os 08 anos de idade.

Enfim, a partir deste estudo foi possível identificar que a ANA, ao compor o SAEB em 2013, foi mais um instrumento de controle e regulação, que orientou as políticas educacionais voltadas à alfabetização nos municípios estudados. Além disto, evidenciamos que a ANA influenciou no direcionamento curricular e na responsabilização docente por meio do PNAIC, que é visto como influência direta nos resultados das avaliações nacionais, inclusive da ANA.

Afirma-se, ainda, que uma vez que este estudo é apenas um levantamento dos dados de uma amostra, não podemos generalizar os resultados e apresentá-los como verdades inquestionáveis, pois se entende que os resultados expostos nesta pesquisa podem fomentar novas questões a serem pensadas e investigadas, a fim de contribuir ainda mais para a pesquisa educacional.

\section{REFERÊNCIAS}

BRASIL. Instituto Nacional de Estudos e Pesquisas Educacionais Anísio Teixeira. Avaliação Nacional da Alfabetização: documento básico. Brasília, DF: INEP, 2013a. 20 p. Disponível em: <http://portal.inep.gov.br/ web/guest/educacao-basica/saeb/sobre-a-ana>. Acesso em: 15 dez. 2016.

BRASIL. MEC/INEP. Avaliação Nacional da Alfabetização: relatório 2013-2014. Vol. 2: análise dos resultados. Brasília, DF: Inep, 2015a. 120 p. Disponível em: <http://portal.inep.gov.br/documents/186968/484421/Relat\%C3\% B3rio+ANA+ 2013-2014+-+An\%C3\%A1lise+dos+Resultados/e2a3d935-7f59-4aba-bb51-2d2ee2d89963?version=1.3 >. Acesso em: 03 mar. 2017.

Pacto Nacional pela Alfabetização na Idade Certa: Caderno de apresentação. Brasília, 2015b. 76 p. Disponível em: <http://pacto.mec.gov.br/images/pdf/Cadernos_2015/cadernos_novembro/pnaic_cad_apresentacao.pdf >. Acesso em: 20 dez. 2016.

Planejando a Próxima Década: Conhecendo as 20 Metas do Plano Nacional de Educação. Secretaria de Articulação com os Sistemas de Ensino (MEC/SASE), 2014. Disponível em: <http://pne.mec.gov.br/images/ pdf/pne_conhecendo_20_metas.pdf $>$. Acesso em: 02 mar. 2017.

Portaria Ministerial 931, de 21 de março de 2005. Sistema de Avaliação da Educação Básica. Diário Oficial da União, Brasília, DF, n. 55, 22 de março de 2005. Seção1. Disponível em: <http://download.inep.gov.br/educacao_ basica/prova_brasil_saeb/legislacao/Portaria931_NovoSaeb.pdf>. Acesso em: 20 mar. 2017.

Portaria 482, 7 de junho de 2013. Sistema de Avaliação da Educação Básica. Diário Oficial da União, Brasília, DF, p. 17, 10 jun. 2013b. Seção1. Disponível em: <http://download.inep.gov.br/educacao basica/ prova_brasil_saeb/legislacao/2013/portaria_n_482_07062013_mec_inep_saeb.pdf>. Acesso em: 30 maio 2017.

. Portaria 867, de 4 de julho de 2012. Institui o Pacto Nacional pela Alfabetização na Idade Certa e as ações do Pacto e define suas diretrizes gerais. Diário Oficial da União, Brasília, DF, n. 129, p. 22, 5 jul. 2012 . Seção 1. Disponível em: 〈http://pacto.mec.gov.br/images/pdf/port_867_040712.pdf〉. Acesso em: 30 abr. 2017. 
DICKEL, A. A avaliação Nacional da Alfabetização no contexto do sistema de avaliação da educação básica e do Pacto Nacional pela Alfabetização na Idade Certa: responsabilização e controle. Cad. Cedes, Campinas, v. 36, n. 99, p. 193-206, maio-ago. 2016. Disponível em: <http://www.scielo.br/pdf/ccedes/v36n99/1678-7110-ccedes-36-9900193.pdf>. Acesso em: 14 abr. 2017. DOI: 10.1590/CC0101-32622016162940.

INSTITUTO NACIONAL DE PESQUISAS EDUCACIONAIS - INEP. Portal eletrônico do Instituto Nacional de Pesquisas Educacionais - INEP, 2018. Disponível em: 〈http://portal.inep.gov.br/web/guest/educacao-basica/saeb〉. Acesso em: 18 fev. 2018.

KOVALCHUK, A. C. D.; LIMA, M. F. A avaliação da Educação Básica no Brasil: um olhar histórico e reflexivo. In: CONGRESSO INTERNACIONAL DE EDUCAÇÃO, 2 2010 , Ponta Grossa - Paraná. Anais... Ponta Grossa Paraná: UEPG, 2010. Disponível em: <www.isapg.com.br/2010/ciepg/download.php?id>. Acesso em: 17 dez. 2016.

MASCARO, A. L. Estado e forma política. $1^{\circ}$ ed. São Paulo: Boitempo, 2013.

MAUÉS, O. C. O papel da escola na construção dos saberes e os limites da noção competência. In: FERREIRA, E. B.; OLIVEIRA, D. A. (Orgs.). Crise da escola e políticas educativas. $2^{\circ}$ ed. Belo Horizonte: Autêntica Editora, 2013. p. 287- 307.

MENEGÃO, R. C. S. G. Os impactos da avalição em larga escala nos currículos escolares. Práxis Educativa, Ponta Grossa - PR, v. 11, n. 3, p. 641-656, set./dez. 2016. Disponível em: <http://www.revistas2.uepg.br/index.php/praxi seducativa>. Acesso em: 28 abr. 2017.

OLIVEIRA, J.F. A função social da escola pública: tensões, desafios e perspectivas. In: FERREIRA, E.B.; OLIVEIRA, D.A. (Orgs). Crise da escola e políticas educativas. $2^{\circ}$ ed. Belo Horizonte: Autentica Editora, 2013. p. $237-252$.

PAINEL EDUCACIONAL. Portal eletrônico do Instituto Nacional de Pesquisas Educacionais - INEP, 2018. Disponível em: <http://portal.inep.gov.br/painel-educacional>. Acesso em: 01 jul. 2018.

PIRES, A.P.; SCHNECKENBERG, M. Política de formação continuada de professores: o PNAIC e o desafio da alfabetização na idade certa. Revista CAMINE: Caminhos da Educação, Franca - SP, v. 7, n. 2, p. 103- 126, 2015. Disponível em: <https://ojs.franca.unesp.br/index.php/caminhos/article/view/1391〉. Acesso em: 03 maio 2017.

SANTOS, R. L. L. Sistema Nacional de Avaliação da Educação Básica: situando olhares e construindo perspectivas. 2007. 184 f. Tese Doutorado em educação: Currículo - Pontifica Universidade Católica de São Paulo, 2007. Disponível em: <https://sapientia.pucsp.br/bitstream/handle/9975/1/Regina\%20L\%20L\%20Santos.pdf.>. Acesso em: 29 dez. 2016.

SCHNEIDER, M. P.; ROSTIROLA, C. R. Estado-Avaliador: reflexões sobre sua evolução no Brasil. Revista Brasileira de Política e Administração da Educação (RBPAE) - Associação Nacional de Política e Administração da Educação (ANPAE), v. 31, n. 3, p. 493-510, set./dez. 2015. Disponível em: <http://seer.ufrgs.br/index.php/rbpae/ article/view/63790>. Acesso em: 02 maio 2017. DOI10.21573/vol31n32015.6379.

SOUSA. S. M. Z. L. Avaliação do rendimento escolar como instrumento de gestão educacional. In: OLIVEIRA, D. A. (org.). Gestão democrática da educação. 10. ed. Petrópolis, RJ: Editora Vozes, 2013. p. 264- 283. 


\section{RESUMO}

O artigo teve por objetivo investigar as políticas de avaliação em nível federal, priorizando a análise da Avaliação Nacional da Alfabetização (ANA), buscando localizar a avaliação nacional no contexto das políticas neoliberais, assim como caracterizar a ANA no que se refere às suas formas e objetivos. Inicialmente apresenta o referencial teórico com a discussão sobre as políticas avaliativas no Brasil no contexto neoliberal; e em seguida, os dados quantitativos da ANA em dois municípios da Região Sudeste do Paraná. Esta avaliação interfere no direcionamento curricular e é um instrumento de regulação e controle por parte do Estado.

Palavras-chave: Políticas de Avaliação da Educação Básica. Avaliação Nacional da Alfabetização (ANA). Política Educacional.

\section{AVALIACIÓN NACIONAL DE LA ALFABETIZACIÓN (ANA): UN ESTUDIO PRELIMINAR}

\section{RESUMEN}

El artículo tuvo el objetivo de investigar las políticas de evaluación a nivel federal, priorizando el análisis de la Evaluación Nacional de la Alfabetización (ANA in su acrónimo en portugués), buscando localizar la evaluación nacional en el contexto de las políticas neoliberales, así como caracterizar la ANA en lo que se refiere a sus formas y objetivos. Inicialmente presenta el referencial teórico con la discusión sobre las políticas evaluativas en Brasil, en el contexto neoliberal; y en seguida, los datos cuantitativos del ANA en dos municipios de la Región Sudeste de Paraná-Brasil. Esta evaluación interfiere en el direccionamiento curricular y es instrumento de regulación y control por parte del Estado.

Palabras clave: Políticas de Evaluación de la Educación Básica. Evaluación Nacional de la Alfabetización (ANA). Política Educacional.

\section{NATIONAL LITERACY ASSESMENT (ANA): A PRELIMINARY STUDY}

\section{ABSTRACT}

The issue had as aim to investigate the evaluation policies at federal level, prioritizing the National Literacy Assessment (ANA in Portuguese acronym), searching to localize the national assessment in the neoliberal policies context, as well as characterize the ANA regarding to its forms and goals. Initially it presents the theoretical referential with discussion on the assessment policies in Brazil in the neoliberal context; and next, quantitative data from ANA in two municipalities of Southwest Region of Paraná-Brazil. This evaluation interferes on curriculum addressment and it is a regulation instrument used by the State.

Keywords: Basic Education Assessment Policies. National Literacy Assessment (ANA). Educational Policy. 